\title{
056 POTENTIAL CONTRIBUTORS TO THE LOW PERFORMANCE OF PREVENTION OF MOTHER-TO-CHILD TRANSMISSION (PMTCT) OF HIV PROGRAMS IN RURAL ETHIOPIA: HEALTH SYSTEMS PERSPECTIVE
}

Anteneh Asefa, ${ }^{1}$ Habtamu Beyene ${ }^{2}$. 'School of Public Health, Hawassa University, Hawassa, Ethiopia; ${ }^{2}$ Disease Prevention and Health Promotion, SNNPR Health Bureau, Hawassa, Ethiopia

\subsection{6/bmjopen-2015-forum2015abstracts.56}

Background Though Ethiopia has achieved a 25\% decline in new HIV infections, new infections among children is still pressingly high; which is by far attributable to low performance of PMTCT program.

Objectives This study is aimed at identifying the contributors to low performance of PMTCT program.

Methods A mixed-method and health-institution based cross sectional study was conducted in March 2012 in rural communities of Southern Ethiopia. A linear model of health systems thinking (inputàprocessàoutput) was used to gather necessary information. The study involved face-to-face interviews with 1325 pregnant women and 62 service providers, 10 focus group discussions with pregnant women, 19 key-informant interviews with PMTCT service coordinators, and facility assessment of 62 rural health centers. Quantitative data were managed using SPSS version 16 software whereas thematic analysis of the qualitative data was done manually.

Result Only $60.7 \%$ and $23.1 \%$ of women were aware about the possibility of MTCT and had a discussion on HIV with their male partner respectively. Service providers delivered information on HIV and MTCT/PMTCT to only $70.2 \%$ and $41 \%$ of the women respectively. Besides, $25.8 \%$ of providers feel that they are emotionally drained by their PMTCT work. Antiretroviral drugs were reported to have been never available in $16 \%$ of the surveyed health facilities. Incomplete or no maternal knowledge on MTCT, low male partner involvement and support in HIV testing and maternal health services, and home delivery, were the demand side themes identified to have negatively affected PMTCT program. On the other hand, weak referral system between rural health centers and their catchment health posts, weak community level PMTCT interventions, inadequate management support, high trained staff turnover, low confidence in handling HIV positive mothers, and stock outs of logistics were contributors from the supply side.

Conclusion There are multitudes of health systems elements confronting PMTCT program in the study area which are largely intertwined and avoidable. Primary health care units, district and zonal health departments, and other allies should address the identified contributors to improve the PMTCT program.

\section{REFERENCES}

1 HIV/AIDS Estimates and Projections in Ethiopia 2011-2016. Available at http://www. etharc.org/resources/healthstat/hivaids-estimates-andprojections-in-ethiopia-20112016 (accessed 7 Dec 2013).

2 Federal Ministry of Health: Accelerated Plan for Scaling Up Prevention of Mother to Child Transmission (PMTCT) Services in Ethiopia. Addis Ababa: Federal Ministry of Health, 2011.

3 Central Statistical Agency: Ethiopian Demographic and Health Survey, 2011. Addis Ababa: Central Statistical Agency, 2012. 